\title{
Beacon of hope: Evaluation of the Kenya Girl Guides Association HIV/AIDS program for school children
}

\author{
Karusa Kiragu \\ George Odingo \\ Population Council \\ Milka Juma \\ Jane Mbugua \\ Magdalen Waweru
}

See next page for additional authors

Follow this and additional works at: https://knowledgecommons.popcouncil.org/departments_sbsr-hiv

Part of the Demography, Population, and Ecology Commons, Gender and Sexuality Commons, Health Policy Commons, Immune System Diseases Commons, International Public Health Commons, Medicine and Health Commons, Public Health Education and Promotion Commons, and the Virus Diseases Commons

How does access to this work benefit you? Let us know!

\section{Recommended Citation}

Kiragu, Karusa, George Odingo, Milka Juma, Jane Mbugua, Magdalen Waweru, Wamuyu Mahinda, Beatrice Mwaniki, Charity Muturi, Simon Ochieng, Tobey C. Nelson, and Ann P. McCauley. 2007. "Beacon of hope: Evaluation of the Kenya Girl Guides Association HIV/AIDS program for school children," Horizons Final Report. Washington, DC: Population Council. 


\section{Authors}

Karusa Kiragu, George Odingo, Milka Juma, Jane Mbugua, Magdalen Waweru, Wamuyu Mahinda, Beatrice Mwaniki, Charity Muturi, Simon Ochieng, Tobey C. Nelson, and Ann P. McCauley 


\section{Hprizons}

Beacon of Hope:

Evaluation of the

Kenya Girl Guides Association

HIV/AIDS Program for

School Children
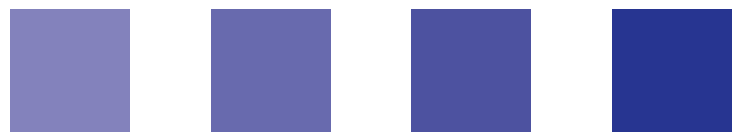

Horizons Program

PATH

Kenya Girl Guides Association

Family Health International

International Center for Research on Women 


\title{
Beacon of Hope: Evaluation of the Kenya Girl Guides Association HI V/ AI DS Program for School Children
}

\author{
Karusa Kiragu ${ }^{1}$, George Odingo ${ }^{2}$, Milka J uma ${ }^{3}$, Jane Mbugua ${ }^{4}$, \\ Magdalen Waweru ${ }^{4}$, Wamuyu Mahinda ${ }^{4}$, Beatrice Mwaniki ${ }^{4}$, Charity Muturi ${ }^{5}$, \\ Simon Ochieng ${ }^{5}$, Tobey Nelson ${ }^{6}$, and Ann McCauley ${ }^{7}$
}

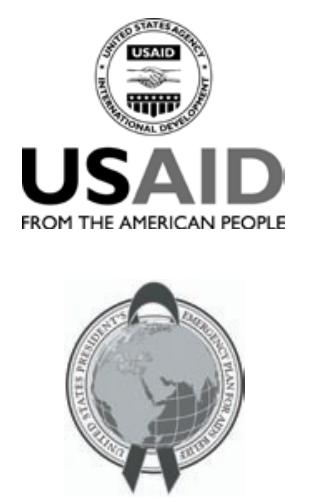

\section{${ }^{\mathrm{H}} \mathrm{R}^{\text {rizons }}$}
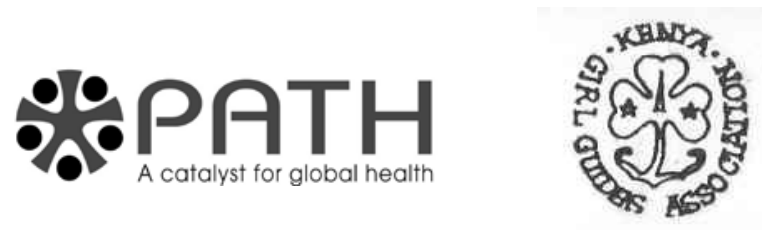

${ }^{1}$ Horizons/PATH

${ }^{2}$ Horizons/Population Council

${ }^{3}$ Formerly of Horizons/Population Council

${ }^{4}$ Kenya Girl Guides Association

${ }^{5}$ Family Health International

${ }^{6}$ Horizons/International Center for Research on Women

${ }^{7}$ Formerly of Horizons/International Center for Research on Women

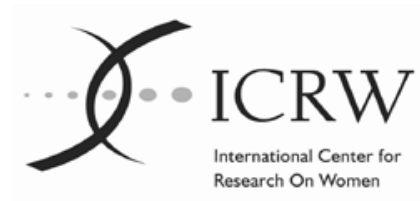




\section{Acknowledgments}

The principle investigators for this study were Milka Juma (formerly with Horizons/Population Council, Nairobi), Ann McCauley (formerly with Horizons/International Center for Research on Women, Washington DC), Karusa Kiragu (Horizons/PATH, Nairobi) and Tobey Nelson (Horizons/International Center for Research on Women, Washington DC). Data collection and management were supervised by George Odingo and Scott Geibel (Horizons/Population Council, Nairobi). Alison Lee (formerly of Horizons/Population Council, Washington DC) copyedited the report. Julie Pulerwitz (Horizons/PATH, Washington, DC) and Ellen Weiss (Horizons/International Center for Research on Women, Washington DC) reviewed earlier drafts, and Sherry Hutchinson (Horizons/Population Council, Washington DC) oversaw the layout.

This report presents findings from an evaluation of an intervention that was implemented by the Kenya Girl Guides Association (KGGA), with technical guidance from Family Health International (FHI) and PATH. The research team would like to thank the following individuals at the KGGA for their tireless efforts: Mrs. Honorine Kiplagat (former National Chairman), Mrs. Margaret Mwaniki (former Chief Commissioner), Debbie Gachuhi (Independent Consultant), Mrs. Alice Waweru (Project Executive), Mrs. D.P. Shah (former Assistant Chief Commissioner), Mrs. Naomi Zani (Provincial Coordinator, Coast), and Mrs. Wamuyu Mahinda (current Chief Commissioner). Gratitude is also extended to Mrs. Jane Mbugua (Project Officer, HIV/AIDS) and Mrs. Magdalen Waweru (National Trainer, HIV/AIDS) for their exceptional support during all phases of the research. The study team benefited greatly from the KGGA District Coordinators and from the Ministry of Education Offices in the study sites. At FHI, the appreciation is extended to Charity Muturi, Simon Ochieng, Maryann Pribila and Peter Mwarogo. At PATH, the study team would like to thank Rikka Transgrud and Michelle Folsom.

Special appreciation is extended to the Girl Guides, fellow students and Guide Leaders, who kindly answered the questionnaires and participated in the study. We are also grateful to the school management for enabling the research to be implemented in their facilities.

The authors are grateful to the United States Agency for International Development (USAID) through PEPFAR, for funding this evaluation.

\footnotetext{
This study was supported by the Horizons Program, which is implemented by the Population Council in collaboration with the International Center for Research on Women, International HIV/AIDS Alliance, PATH, Tulane University, Family Health International, and Johns Hopkins University. Horizons is

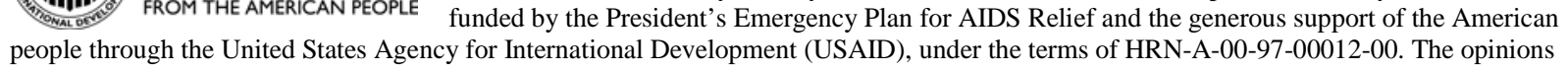
expressed herein are those of the authors and do not necessarily reflect the views of the U.S. Agency for International Development.
}

Published in August 2007.

\section{(2) Population Council}

The Population Council is an international, non-profit, nongovernmental institution that seeks to improve the well-being and reproductive health of current and future generations around the world and to help achieve a humane, equitable, and sustainable balance between people and resources. The Council conducts biomedical, social science, and public health research and helps build research capacities in developing countries. Established in 1952, the Council is governed by an international board of trustees. Its New York headquarters supports a global network of regional and country offices.

Copyright $@$ 2007. The Population Council Inc.

Suggested citation: Kiragu, Karusa, George Odingo, Milka Juma, Jane Mbugua, Magdalen Waweru, Wamuyu Mahinda, Beatrice Mwaniki, Charity Muturi, Simon Ochieng, Tobey Nelson, and Ann McCauley. 2007. "Beacon of hope: Evaluation of the

Kenya Girl Guides Association HIV/AIDS program for school children,” Horizons Final Report. Washington, DC: Population Council.

This document may be reproduced in whole or in part without permission of the Population Council provided full source citation is given and the reproduction is not for commercial purposes. 


\section{Table of Contents}

$\begin{array}{ll}\text { Executive Summary } & 1\end{array}$

$\begin{array}{ll}\text { Introduction } & 2\end{array}$

Methods and Study Population 3

Study design 3

Data collection 3

Data analysis $\quad 4$

Ethical considerations $\quad 4$

$\begin{array}{ll}\text { Study population } & 4\end{array}$

Intervention $\quad 6$

Description of the KGGA HIV/AIDS Peer Education Program $\quad 6$

$\begin{array}{ll}\text { Intervention implementation } & 7\end{array}$

$\begin{array}{ll}\text { Intervention exposure } & 8\end{array}$

$\begin{array}{lr}\text { Results } & 9\end{array}$

Changes in self-confidence and social connectedness 9

$\begin{array}{ll}\text { Changes in attitudes toward gender equity } & 10\end{array}$

Changes in attitudes toward people living with HIV 12

Knowledge of HIV and AIDS 14

Sexual behavior $\quad 15$

Perceptions of the intervention $\quad 16$

$\begin{array}{ll}\text { Discussion and Recommendations } & 19\end{array}$

$\begin{array}{ll}\text { References } & 22\end{array}$ 



\section{Executive Summary}

This report presents finding from an evaluation of the Kenya Girl Guides Participatory Peer Education Program for HIV and AIDS Prevention. The objective of the program was to train Girl Guide Patrol Leaders as peer educators, who in turn, would communicate key information and concepts about such topics as HIV prevention, relationships, and self-esteem, to other Girl Guides, and ultimately to their school peers. The evaluation employed a quasi-experimental research design, with a baseline survey conducted in late 2004 and an endline survey 12 months later. The research was conducted in four districts (two intervention and two comparison) in the Rift Valley and Coast Provinces of Kenya. Data were collected from Girl Guides and their school male and female peers using an interviewer-assisted, self-administered questionnaire. The baseline survey was administered to 1,986 youth (1,109 from intervention and 877 from comparison schools). At endline, 2,192 youth (1,160 from intervention and 1,032 from comparison sites) were surveyed. About half the respondents were Girl Guides. Nearly 75 percent of the sample was female, most respondents attended rural schools, and the mean age of the sample was 12.4 years (range 10 to 14 years).

Logistic regression analysis suggests that the program was associated with several favorable outcomes among the Girl Guides. Girl Guides performed better than their non-guiding male and female peers with regards to social well-being, support for gender equity, acceptance of people living with HIV, and knowledge of HIV and AIDS. The results demonstrate that peer education conducted by Girl Guides is a feasible strategy for imparting HIV and AIDS education to school-going youth; however, such a program would need to be branded, strengthened, and appropriately resourced to attain positive results that extend beyond the Girl Guides to include their peers. The results also demonstrate that school girls in this study are operating in an environment where their male counterparts are more than seven times as likely to be sexually experienced, and may be exerting considerable pressure to have sex even on the strongest of girls. HIV risk-reduction programs directed at school girls may be more successful if they also address the risk behavior of school boys. 


\section{Hgrizons}

\section{Introduction}

It is widely acknowledged that the future direction of the AIDS epidemic will largely be shaped by the current behaviors of society's adolescents (UNAIDS 2004). In Kenya, the reduction of sexual risk-taking among youth has been credited with contributing to the recent nationwide decline in HIV prevalence: a comparison of the 1993 and 2003 Kenya Demographic and Health Survey shows that the median age at sexual debut among girls increased by a full year over the decade, from 16.8 years to 17.8 years. For boys, the increase was from 16.8 years to 17.1 years. There was also a sharp drop in multiple partnerships, especially among young men. In 1993, nearly 60 percent of males ages 20-24 years reported having more than one sexual partner in the six months preceding the survey, but by 2003, only 16 percent reported more than one partner. Although girls have historically had fewer sexual partners than boys, there was also a decline measured among them. Among females ages 15-24 years, less than 4 percent had multiple partners in the six months before the 1993 survey. In 2003, this figure had dropped to 2 percent in the 12 months before the survey. The partner reduction among females was even more significant in 2003 since it covered a longer reference period than in 1993 (MOH 2005).

Globally, girls are more vulnerable to HIV than boys, as a result of biological, social, and economic factors. In Kenya, for every HIV-infected male between the ages of 20 and 24 years, there are nearly four infected females in the same age range. Among the youngest adolescents, the gender differentials are even greater: for every HIV-infected male between the ages of 15 and 19 years, there are nearly eight infected female age mates (MOH 2005). Thus, there is a compelling urgency to address HIV risk among adolescent girls.

To reduce sexual risk among school-going adolescents in Kenya, the Kenya Girl Guides Association (KGGA) implemented the Kenya Girl Guides Participatory Peer Education Program for HIV and AIDS Prevention, more commonly known as the KGGA HIV/AIDS Peer Education Program. The initiative commenced in 1999 under the USAID-funded Implementing AIDS Prevention and Care (IMPACT) Project, managed by Family Health International (FHI). Technical assistance was provided by PATHKenya. The KGGA HIV/AIDS Peer Education Program was conducted in addition to existing Girl Guide activities. Its objectives were to provide girls and young women between the ages of 6 and 25 years with an opportunity to learn more about themselves, relationships, communication, their values, and factors that influence their feelings about themselves; to assist them in making decisions related to their sexual and reproductive health, and to increase their knowledge about STIs/HIV/AIDS.

Horizons was requested to assess the impact of the peer education program as it scaled up to new schools. The evaluation was conducted in districts that had ongoing Girl Guide activities but had not yet started the HIV/AIDS Peer Education Program. The purpose of the assessment was to determine if involvement in the program had an effect on the social well-being and gender- and HIV-related attitudes, knowledge, and behavior of the Peer Educators and their fellow Girl Guides. In addition, the study sought to examine the ripple effect of the program, i.e., its impact on male and female students outside of the Girl Guide program. This report presents the results of that evaluation. 


\section{Methods and Study Population}

\section{Study Design}

Horizons conducted a quasi-experimental study to assess the impact of the Kenya Girl Guides Association's HIV/AIDS Peer Education Program. Quantitative and qualitative data were collected from schools in two intervention districts (Nakuru and Malindi) and schools in two comparison districts (Kericho and Kilifi) in the Rift Valley and Coast provinces of Kenya.

\section{Data Collection}

\section{Quantitative surveys}

Baseline data were collected in intervention and comparison schools prior to implementation, and followup data were collected one year later. The baseline survey was administered to pupils in 58 schools and the follow-up survey to pupils in 50 schools. The study included both urban and rural schools.

Data were gathered using an anonymous, pre-tested, interviewer-assisted, self-administered questionnaire. Pre-tests revealed many gaps in the self-administered instruments, particularly those with skip patterns. The research team then decided to have two research assistants present in a class during questionnaire administration. While one researcher read out each question and all its options aloud, the second researcher walked around and answered any questions. The strategy lengthened the time required to collect the data, but was deemed the most effective method for minimizing missing values and inappropriate responses. All efforts were made to ensure that the respondents were able to answer the questions confidentially and anonymously.

Questionnaires were administered in both Kiswahili and English. Questions were multiple-choice. The research assistants received a five-day training and the same team that facilitated the administration of the baseline survey did so for the follow-up survey. To minimize student discomfort, teachers were not allowed in the classrooms during data collection.

\section{Focus group discussions}

Before commencement of the intervention, focus group discussions (FGDs) were conducted in both the intervention and comparison sites. A total of 24 FGDs of 8-12 participants were conducted with Girl Guides (8), male peers (7), and female peers (9). After the intervention, 21 FGDs were held with adolescents, again in both intervention and comparison schools. They consisted of eight FGDs with Girl Guides, five with male peers, and eight with female peers.

In addition to FGDs with the pupils, four FGDs with Guide Leaders were held after the intervention. These FGDs were only held in Malindi and Naivasha, the two districts where the HIV/AIDS Peer Education Program had been implemented. The FGDs included nine Guide Leaders each, resulting in discussions with 36 teachers. 


\section{Hgrizons}

\section{Data Analysis}

Baseline and follow-up survey results were compared by intervention versus comparison sites and by guiding status (i.e., comparing Girl Guides to their male and female peers). Inter-group analysis revealed that the results of the Girl Guide Peer Educators were largely similar to those of the other Girl Guides. Therefore these two groups were combined in the analysis and referred to as "Girl Guides," in order to make the results more stable and the sample sizes comparable to other sub-groups. Bivariate analysis was employed to assess preliminary associations between the exposure variable and the outcomes of interest.

Multivariate analysis was conducted to assess the association between the intervention and the desired outcomes by applying logistic regression in the follow-up data. Specifically, logistic regression analysis compared the outcomes among the girls in the comparison schools to students in the intervention schools and specifically: a) the Girl Guides, b) the female schoolmates of the Girl Guides, and c) the male schoolmates of the Girl Guides. The measure of association was the odds ratio (Hosmer and Lemeshow 2000). Outcome variables were dichotomized at the mean. The analysis controlled for age and urban-rural location of the school. Because the guiding status variable already contained a male and female subgroups, the data are self-controlling for sex, and therefore sex is not introduced in the equation because of colinearity. Data were analysed using Stata v.9.0. A p value of $\leq 0.05$ is considered statistically significant.

Qualitative data were transcribed and the research team reviewed transcripts and determined key themes for coding and interpretation of study findings. The transcripts for all the FGDs were then analyzed using the qualitative analysis software NUD*IST.

\section{Ethical Considerations}

The study received ethical approval from the Population Council's internal review board and from Kenya's National Council for Science and Technology. Approval was also obtained from district gatekeepers and head teachers in the participating schools. A week before data collection, pupils in the participating classes were given informed consent letters for their parents/guardians, and only those who secured written approval were eligible to complete the questionnaire. In addition to parental approval, the researchers also sought consent from the pupils. Pupils unwilling to participate, despite parental approval, would have been excused from the study; however, none refused.

Pupils who were unable to obtain parental consent were excluded from the data collection. This may have inadvertently omitted pupils whose parents/guardians were of a different ideological viewpoint than other parents, those who could not read or write, those who were absent during the consenting period, or those who were willing but unable to consent for other reasons.

\section{Study Population}

All Girl Guides and a random sample of their female and male peers were selected to participate in the surveys in each school. A total of 1,986 pupils were surveyed at baseline between September and November 2004, and 2,192 were surveyed during follow-up 12 months later. Approximately 75 percent of the sample was female. At baseline, there were no Peer Educators, as the program had not yet started 
(see Table 1). At follow-up, 89 Girl Guides reported that they were Peer Educators and had received a three-day Peer Educator training through the HIV/AIDS program. Thus at follow-up there were 89 Peer Educators compared to 490 Girl Guides, 308 male schoolmates (referred to in this report as male peers), and 273 female schoolmates (referred to in this report as female peers).

About three-quarters of respondents attended schools in rural areas. When examined by district, pupils from Nakuru and Kericho districts comprised a larger share of the sample. Nearly 90 percent of respondents were Christian (data not shows).

The sample included pupils from standard 4 to standard 7, aged 10 to 14 years. ${ }^{1}$ While the overall study population was comparable with respect to age and sex, Table 1 reveals that the intervention and the comparison groups were not equivalent at baseline with respect to the proportion of respondents from an urban area (34 percent vs. 18 percent).

Table 1 Demographic characteristics of the respondents

\begin{tabular}{|c|c|c|c|c|}
\hline \multirow[t]{2}{*}{ Characteristics } & \multicolumn{2}{|c|}{ Baseline } & \multicolumn{2}{|c|}{ Follow-up } \\
\hline & $\begin{array}{l}\text { Intervention } \\
(n=1,109)\end{array}$ & $\begin{array}{c}\text { Comparison } \\
(n=877)\end{array}$ & $\begin{array}{l}\text { Intervention } \\
(n=1,160)\end{array}$ & $\begin{array}{c}\text { Comparison } \\
(n=1,032)\end{array}$ \\
\hline \multicolumn{5}{|l|}{ Guiding status (\%) } \\
\hline GG Peer Educators & 0 & 0 & 8 & 0 \\
\hline Regular Girl Guides & 55 & 50 & 42 & 50 \\
\hline Male peers & 25 & 25 & 26 & 25 \\
\hline Female peers & 20 & 25 & 24 & 25 \\
\hline Female (\%) & 75 & 75 & 73 & 75 \\
\hline Age (mean) & 12.3 & 12.4 & 12.3 & 12.4 \\
\hline Urban (\%)* & 34 & $18^{\star \star}$ & 35 & $28^{\star \star}$ \\
\hline \multicolumn{5}{|l|}{ District } \\
\hline Naivasha & $58^{\star *}$ & - & $63^{\star \star}$ & - \\
\hline Malindi & $42^{\star}$ & - & $37^{\star}$ & - \\
\hline Kericho & - & $44^{*}$ & - & $56^{*}$ \\
\hline Kilifi & - & $56^{*}$ & - & $44^{*}$ \\
\hline
\end{tabular}

* Baseline differences between intervention and comparison groups statistically significant $(p \leq 0.05)$

**Baseline to follow-up differences statistically significant $(p \leq 0.05)$

There was also a statistically significant difference within the comparison site between rounds, with a near doubling of the urban sample from 18 percent to 28 percent. There were changes by district between rounds: in the intervention sites, there was an increase in students from Naivasha District from 58 percent at baseline to 63 percent at follow-up, and a decline among those from Malindi. In the follow-up districts, there was an increase in students from Kericho, from 44 percent to 56 percent and a decline among those from Kilifi.

${ }^{1}$ Pupils in the terminal class, standard 8, were excluded from the research since they were preparing for secondary school entry exams. 


\section{Hgrizons}

\section{I ntervention}

\section{Description of the KGGA HIV/ AI DS Peer Education Program}

KGGA members range between 6 and 25 years of age, and its activities are primarily targeted toward primary and secondary school-going girls. Members are grouped into different cadres by age group: Brownies (6-9 years), Girl Guides (10-14 years), Rangers (15-18 years), and Cadets (19-25 years). Each cadre is organized into groups of 10 girls (patrols) headed by a Patrol Leader of the same age. Each school generally has one teacher who volunteers her time to serve as Guide Leader. This Guide Leader is in charge of Guide activities in the school.

This evaluation focused on the HIV/AIDS Peer Education program implemented by the Girl Guide cadre (ages 10-14). Schools participating in the KGGA program generally have ten Girl Guide Patrols, which each consist of approximately eight Girl Guides and are headed by one Patrol Leader.

\section{The Kenya Girl Guides Association}

The KGGA is a character development organization established to help young girls navigate the path from childhood through adolescence to young adulthood. It has been active in Kenyan schools since 1920, and has a membership of over 100,000 . It is a volunteer organization that places strong emphasis on democratic values, responsibility, community, service, and the promotion of peace.

As part of the HIV/AIDS Peer Education Program, Guide Leaders receive a seven-day training on HIV/AIDS utilizing the training manual Participatory Peer Education for HIV and AIDS Prevention: A Life Skills and Peer Education Manual. The Guide Leaders return to their schools to provide an intensive three-day Peer Education training to Patrol Leaders, who become Peer Educators. The Peer Educators educate the Girl Guides in their patrols on the material in the manual by engaging them in routine discussions, short lectures, case studies, role-playing, games, and brainstorming sessions. Following receipt of this information all Girl Guides in the patrol are expected to act as disseminators by participating in information dissemination activities targeting their schoolmates and community members. This can be done in a number of ways such as composing songs, writing poems, leading dances, or providing other entertainment. Other methods included a suggestion box and inviting special guests to talk to the student body. Girl Guides are also given a chance to educate fellow pupils at assemblies. In addition to KGGA provided materials, Girl Guides may have access to supplementary materials available through their schools, such as UNICEF Sara comics and other behavior change communication (BCC) materials.

The Life Skills and Peer Education Manual focuses on eight topics: I) personal, family, and community values; II) gender roles and equality; III) adolescent development; IV) sexuality; V) relationships; VI) preventing pregnancy; VII) sexually transmitted infections, HIV, and AIDS; and VIII) communication skills and self-esteem. Each topic is divided into four to five units. The manual is designed to be implemented over 39 weeks of Girl Guide sessions by the Peer Educators under the direction of the Guide Leaders. The Guide Leaders could begin sessions on any topic and are instructed to adapt sessions for each guiding age group. All the topics in the manual can be covered over an academic year, depending on the pace at which the Guide Leader shepherds the Peer Educator. 
Various stakeholders approved the Life Skills and Peer Education Manual including the Ministry of Education, parents, and some key representatives of religious and community organizations. It is interactive and audience driven, using exercises, skits, games, and group work. This methodology allows it to be used by adolescents of various age groups. The manual focuses on giving pupils the opportunity to challenge themselves and ask themselves questions. It emphasizes skills-building, enabling pupils to act out scenarios and situations they may encounter.

The key elements of the Life Skills and Peer Education Manual have been condensed into a small userfriendly booklet, “Talking Points” (KGGA, no date). "Talking Points” is the main reference document for the Peer Educators, and it is laminated to withstand frequent use. Each section covers a specific subject and is color-coded to facilitate access during peer education sessions. Each subject has a factual information section, followed by the key take-home messages about the topic, and a short question-andanswer session to test knowledge acquired.

Throughout the school term, Girl Guides meet with their Peer Educators and their Guide Leaders to discuss various topics in the HIV/AIDS manual. These discussions are conducted in the context of other ongoing Girl Guide activities and Patrol meetings. Meetings take place in classrooms, outdoors, or in other venues as appropriate. They are generally held in the afternoon after school lessons have formally ended, and while other extracurricular activities are taking place. The frequency and intensity of these activities is site-specific and dependent on the KGGA structure within each school. Thus the intensity with which the KGGA HIV/AIDS Peer Education Program is implemented depends on the commitment of the school management and Guide Leader.

As part of the KGGA HIV/AIDS Peer Education Program, KGGA also integrated a new HIV/AIDS badge into the existing badge system. There are HIV/AIDS badges corresponding to each of the cadres within the Girl Guides system. Each cadre is tasked with accomplishing a set of activities ranging in complexity and difficulty to earn the badge.

\section{I ntervention I mplementation}

At the time of the baseline survey, many schools in the study were already implementing the regular Girl Guide program, and those in the intervention districts were simply waiting for the KGGA HIV/AIDS Peer Education Program to start. However, in a few schools, the general Girl Guide program was initiated with the start of the KGGA HIV/AIDS Peer Education Program. Guide Leaders at these schools were expected to start both programs up. This sometimes affected the rate at which the HIV/AIDS program could proceed. The program also had to contend with normal staffing changes in a school, such as transfers, leave, and retirement of Guide Leaders. It was estimated that as many as 1 in 3 trained Guide Leaders dropped out for various reasons before completing the program.

During the endline survey, Girl Guides were asked how long they had been involved in Girl Guiding. About 45 percent of the 89 Peer Educators said they had been Girl Guides for over two years, 33 percent had been for 1-2 years, and 23 percent has been for less than a year. Among regular Girl Guides, 55 percent said they had been Girl Guides for under a year, 22 percent for 1-2 years, and 23 percent for over two years. 


\section{Hgrizons}

There was substantial variation in the implementation of the intervention across sites. Field assessments and discussions with Guide Leaders revealed that many schools had not completed the entire curriculum by endline data collection; indeed most had gone only halfway. While all schools had covered the first two topics (values and gender), many had just started on the others. Topic VII (HIV and AIDS) had generally been "touched on" throughout the year, since it was linked directly and indirectly to the other topics and was part of the Government of Kenya school curriculum. While some Guide Leaders and Peer Educators followed the suggested format in the Life Skills Peer Education Manual, others began with the topics they were most comfortable presenting.

\section{Intervention Exposure}

All Girl Guides in the follow-up survey were asked whether they had heard of the "Girl Guide Participatory Peer Education Program for HIV and AIDS Prevention.” The question was asked at both intervention and comparison sites, in order to assess leakage and "background noise." The results show that 89 percent of the Girl Guides in the intervention sites had heard of the intervention, but so had 63 percent of their counterparts in comparison schools. Discussions with the Guide Leaders revealed that Girl Guides, both in intervention and comparison sites, had been informed about the program.

All Girl Guides were asked whether they were aware of "any girl in your unit who is a Peer Educator as part of this [the Girl Guide] program.” About 82 percent of the Girl Guides in the intervention schools said they were, as did 77 percent of their counterparts in comparison sites. Furthermore, when all Girl Guides were asked whether a Peer Educator had ever talked with them about HIV and AIDS, 70 percent of the Girls Guides in the intervention sites answered affirmatively, as did 64 percent of their counterparts in the comparison sites.

Another important finding was that only about half of the Peer Educators (53 percent) had seen the HIV and AIDS booklet "Talking Points," which had been developed for their use. This may be due to a lack of availability of the book. 


\section{Results}

\section{Changes in Self-confidence and Social Connectedness}

Baseline data showed that pupils in both intervention and comparison sites scored high on questions related to self-confidence and social connectedness, indicating that the young people surveyed generally started the program with a healthy sense of well-being. For example, over 90 percent felt proud of themselves, 99 percent liked going to school, over 90 percent felt they were careful in their decision making processes, and over 85 percent felt that their parents cared about them.

The results showed that pupils in the intervention schools demonstrated more statistically significant improvements in measures of self-confidence between baseline and follow-up than those in the comparison schools. For example, they were more likely to report that they would "not feel guilty if they didn't do what their friends wanted," that they "can refuse to do certain things just because others wanted them to," and that they could "say no to sex" (see Table 2).

\section{Table 2 Self-confidence and social connectedness of pupils at intervention and} comparison schools

\begin{tabular}{|c|c|c|c|c|}
\hline \multirow[t]{2}{*}{ Percent who agree with the following: } & \multicolumn{2}{|c|}{ Intervention } & \multicolumn{2}{|c|}{ Comparison } \\
\hline & $\begin{array}{l}\text { Baseline } \\
(n=1,109)\end{array}$ & $\begin{array}{l}\text { Follow-up } \\
(\mathrm{n}=1,160)\end{array}$ & $\begin{array}{l}\text { Baseline } \\
(\mathrm{n}=877)\end{array}$ & $\begin{array}{l}\text { Follow-up } \\
(n=1,032)\end{array}$ \\
\hline I feel proud of myself & 89 & $93^{*}$ & 91 & $95^{\star}$ \\
\hline I like going to school & 99 & $100^{* \star}$ & 99 & 99 \\
\hline I have many friends & 79 & $76^{*}$ & 80 & $74^{*}$ \\
\hline $\begin{array}{l}\text { I would not feel guilty if I don't do what my } \\
\text { friends want }\end{array}$ & 55 & $62^{*}$ & 52 & 54 \\
\hline $\begin{array}{l}\text { My parents/guardians care about what is } \\
\text { happening to me }\end{array}$ & 88 & $91^{*}$ & 92 & 92 \\
\hline $\begin{array}{l}\text { There is someone to talk to when I am in } \\
\text { need of help }\end{array}$ & 61 & 64 & 70 & $63^{*}$ \\
\hline I am careful about the decisions I make & 92 & 92 & 91 & 91 \\
\hline I feel I can say clearly what I want & 83 & $79 *$ & 84 & 84 \\
\hline $\begin{array}{l}\text { I feel I can refuse to do certain things just } \\
\text { because others want me to }\end{array}$ & 60 & $71^{*}$ & 62 & 64 \\
\hline I feel I can say NO to sex & 79 & $83^{*}$ & 85 & $81^{*}$ \\
\hline
\end{tabular}

${ }^{*}$ Differences between baseline and follow-up statistically significant $(p \leq 0.05)$

**Rounded up from 99.5

An aggregate score assessing self-confidence and social connectedness was calculated (see Table 3). At follow-up Girl Guides in the intervention sites had the highest scores of all the groups. This suggests that 


\section{Hgrizons}

there is an association between Girl Guide program involvement and higher self-confidence and social connectedness.

Table 3 Mean social well-being scores by guiding status at intervention and comparison schools^

\begin{tabular}{lcc|cc}
\hline Item & \multicolumn{2}{c|}{ Intervention } & \multicolumn{2}{c}{ Comparison } \\
& $\begin{array}{l}\text { Baseline } \\
\mathbf{n = 1 , 1 0 9}\end{array}$ & $\begin{array}{c}\text { Follow-up } \\
\mathbf{n = 1 , 1 6 0}\end{array}$ & $\begin{array}{c}\text { Baseline } \\
\mathbf{n = 8 7 7}\end{array}$ & $\begin{array}{c}\text { Follow-up } \\
\mathbf{n = 1 , 0 3 2}\end{array}$ \\
\hline Girl Guides & 7.9 & $8.4^{*}$ & 8.1 & 8.1 \\
Male peers & 7.8 & 7.9 & 8.0 & 8.0 \\
Female peers & 7.7 & 7.8 & 8.1 & $7.6^{*}$ \\
All & 7.8 & $8.1^{*}$ & 8.1 & 8.0 \\
\hline
\end{tabular}

$\wedge^{\wedge}$ Out of 10 possible points

*Differences between baseline and follow-up statistically significant

Logistic regression analysis further highlights this association. When compared to comparison site girls, Girl Guides were 78 percent more likely to provide positive responses to questions about self-confidence and social connectedness (see Table 4).

Table 4 Odds of having high social well-being by guiding status, follow-up survey

\begin{tabular}{lcccc}
\hline Group & $\mathbf{n}$ & Odds ratio & $\mathbf{p}$ value & $\mathbf{9 5 \%} \mathbf{C l}$ \\
\hline Comparison site girls & 771 & 1.00 & & \\
Girl Guides & 579 & 1.78 & 0.00 & $1.43-2.22$ \\
Intervention site female peers & 273 & 0.84 & 0.26 & $0.63-1.13$ \\
Intervention site male peers & 308 & 1.03 & 0.82 & $0.79-1.35$ \\
\hline
\end{tabular}

Note: Controlling for age and urban-rural residence

\section{Changes in Attitudes Toward Gender Equity}

Support for gender equity increased between baseline and follow-up among all pupils in the intervention sites. Specifically, respondents in the intervention sites demonstrated statistically significant improvements for all but one of the six gender-related questions (see Table 5). The most meaningful improvements were in the beliefs that "boys and girls should be treated the same" and that "if a family does not have enough money for school fees, they should treat boys and girls the same.” 
Table 5 Support for gender equity among pupils at intervention and comparison schools Percent who agreed with the following^:

\begin{tabular}{cc|cc}
\multicolumn{2}{c|}{ Intervention } & \multicolumn{2}{c}{ Comparison } \\
$\begin{array}{c}\text { Baseline } \\
(\mathbf{n = 1 , 1 0 9 )}\end{array}$ & $\begin{array}{c}\text { Follow-up } \\
(\mathbf{n = 1 , 1 6 0 )}\end{array}$ & $\begin{array}{c}\text { Baseline } \\
(\mathbf{n}=\mathbf{8 7 7})\end{array}$ & $\begin{array}{c}\text { Follow-up } \\
(\mathbf{n}=\mathbf{1 , 0 3 2})\end{array}$ \\
\hline 76 & $81^{*}$ & 74 & 75 \\
67 & $75^{\star}$ & 68 & 64 \\
& & & \\
55 & $62^{\star}$ & 59 & 61 \\
69 & $74^{*}$ & 75 & 75 \\
67 & $72^{*}$ & 73 & 72 \\
94 & 94 & 94 & 96 \\
& & & \\
\hline
\end{tabular}

*Differences between baseline and follow-up statistically significant $(p \leq 0.05)$

^ Statements paraphrased slightly to facilitate data interpretation

An aggregate score calculated to assess attitudes toward gender equity highlights that adolescents in intervention schools were significantly more likely to demonstrate improvements than those pupils in comparison schools (see Table 6). In the intervention sites, Girl Guides scored higher than all the other groups, suggesting a strong association between being a Girl Guide and having gender equitable attitudes.

Table 6 Mean gender equity scores by guiding status in intervention and comparison schools^

\begin{tabular}{lcc|cc}
\hline Item & \multicolumn{2}{c|}{ Intervention } & \multicolumn{2}{c}{ Comparison } \\
& Baseline & Follow-up & Baseline & Follow-up \\
& $(\mathbf{n = 1 , 1 0 9 )}$ & $(\mathbf{n = 1 , 1 6 0 )}$ & $(\mathbf{n = 8 7 7 )}$ & $(\mathbf{n = 1 , 0 3 2 )}$ \\
\hline Girl Guides & 4.6 & $5.0^{*}$ & 4.5 & $4.8^{*}$ \\
Male peers & 3.5 & $3.8^{\star}$ & 4.0 & 3.7 \\
Female peers & 4.4 & 4.5 & 4.6 & $4.4^{*}$ \\
All respondents & 4.3 & $4.6^{*}$ & 4.4 & 4.4 \\
\hline
\end{tabular}

^Out of a possible 6 points

*Differences between baseline and follow-up statistically significant ( $p \leq 0.05$ )

Again, logistic regression supports this association. Compared to girls in the comparison site schools, Girl Guides were 60 percent more likely to support the gender equity items, while their female and male school mates were significantly less likely to do so (see Table 7). 


\section{Hgrizons}

Table 7 Odds of supporting gender equity by guiding status, follow-up survey

\begin{tabular}{lcccc}
\hline Group & $\mathbf{n}$ & Odds ratio & $\mathbf{p}$ value & $\mathbf{9 5 \%} \mathbf{C l}$ \\
\hline Comparison site girls & 771 & 1.00 & & \\
Girl Guides & 579 & 1.60 & 0.00 & $1.26-2.04$ \\
Intervention site female peers & 273 & 0.67 & 0.01 & $0.50-0.88$ \\
Intervention site male peers & 308 & 0.36 & 0.00 & $0.28-0.48$ \\
\hline
\end{tabular}

Note: Controlling for age and urban-rural residence

Focus group discussions with Girl Guides further supported this association, as indicated in the following response to the question, "should boys be treated better than girls?"

[No.] We are the same; we have brains like the boys. Even in class, we girls are brighter than boys.

Girl Guide, Naivasha intervention site

\section{Changes in Attitudes Toward People Living with HIV}

Respondents were read a series of questions designed to assess stigma toward people living with HIV. The follow-up data show that adolescents in the intervention sites were more likely to report positive changes in their attitudes toward and acceptance of people living with HIV (see Table 8). For example, they were more likely to be "willing to care for a HIV-positive family member", "buy food from a person living with HIV", and "play with an AIDS-affected orphan." They were also more likely not to be "fearful of people living with HIV" and to feel that they "should not be separated from other people." However, it is important to note that while the proportion of pupils in intervention schools that said they would buy food from a person living with HIV increased ( 33 percent to 44 percent, $p \leq 0.05$ ), more than half the adolescents in the intervention sites still would not be willing to buy food from people living with HIV. 
Table 8 Attitudes toward people living with HIV among pupils at intervention and comparison schools

\begin{tabular}{|c|c|c|c|c|}
\hline \multirow[t]{2}{*}{ Percent who: } & \multicolumn{2}{|c|}{ Intervention } & \multicolumn{2}{|c|}{ Comparison } \\
\hline & $\begin{array}{c}\text { Baseline } \\
\% \\
(n=1,109)\end{array}$ & $\begin{array}{c}\text { Follow-up } \\
\% \\
(n=1,160)\end{array}$ & $\begin{array}{c}\text { Baseline } \\
\% \\
\text { (n = 877) }\end{array}$ & $\begin{array}{c}\text { Follow-up } \\
\% \\
(\mathrm{n}=1,032)\end{array}$ \\
\hline $\begin{array}{l}\text { Would be willing to care for family member living } \\
\text { with HIV }\end{array}$ & 85 & $93^{*}$ & 93 & 90 \\
\hline Would buy food from shopkeeper living with HIV & 33 & $44^{*}$ & 32 & 34 \\
\hline $\begin{array}{l}\text { Would be willing to play with child whose parents } \\
\text { died of AIDS }\end{array}$ & 73 & $84^{*}$ & 76 & $81^{*}$ \\
\hline Are not afraid of people because they have AIDS & 48 & $51^{*}$ & 51 & 52 \\
\hline $\begin{array}{l}\text { Feel that people living with HIV should not be } \\
\text { separated from other people }\end{array}$ & 69 & $77^{*}$ & 80 & $74^{*}$ \\
\hline
\end{tabular}

*Differences between baseline and follow-up statistically significant $(p \leq 0.05)$

Respondents in the comparison sites showed no statistically significant changes between baseline and follow-up, except on one item: willingness to play with an AIDS orphan. Further, this group showed a statistically significant change in the wrong direction on another item: at follow-up, more believed that "people living with HIV should be separated from other people."

An aggregate measure of attitudes towards people living with HIV demonstrates that respondents in the intervention group possessed more positive attitudes than those in the comparison sites at follow-up, and that the Girl Guides again had the highest mean score, indicating that they had the most supportive attitudes of all the groups (see Table 9).

Table 9 Mean score for positive attitudes toward people living with HIV by guiding status at intervention and comparison schools ${ }^{\wedge}$

\begin{tabular}{|c|c|c|c|c|}
\hline \multirow[t]{2}{*}{ Item } & \multicolumn{2}{|c|}{ Intervention } & \multicolumn{2}{|c|}{ Comparison } \\
\hline & $\begin{array}{c}\text { Baseline } \\
(n=1,109)\end{array}$ & $\begin{array}{l}\text { Follow-up } \\
(\mathrm{n}=1,160)\end{array}$ & $\begin{array}{l}\text { Baseline } \\
(\mathrm{n}=\mathbf{8 7 7})\end{array}$ & $\begin{array}{l}\text { Follow-up } \\
(n=1,032)\end{array}$ \\
\hline$\overline{\text { Girl Guides }}$ & 3.1 & $3.7^{*}$ & 3.3 & 3.5 \\
\hline Male peers & 3.1 & 3.4 & 3.4 & 3.4 \\
\hline Female peers & 2.9 & $3.2^{*}$ & 3.2 & $3.0^{*}$ \\
\hline All respondents & 3.1 & 3.5 & 3.3 & 3.3 \\
\hline
\end{tabular}

^Out of a possible 5 points

*Differences between baseline and follow-up statistically significant $(p \leq 0.05)$

Logistic regression analysis shows that compared to females in comparison site schools, Girl Guides were 64 percent more likely to have positive attitudes toward people living with HIV, while the other groups were no different from the comparison site girls (see Table 10). 


\section{Hgrizons}

Table 10 Odds of having positive attitudes toward people living with HIV by guiding status, follow-up survey

\begin{tabular}{lcccc}
\hline Group & $\mathbf{n}$ & Odds ratio & $\mathbf{p}$ value & $\mathbf{9 5 \%} \mathbf{~ C l}$ \\
\hline Comparison site girls & 771 & 1.00 & & \\
Girl Guides & 579 & 1.64 & 0.00 & $1.32-2.05$ \\
Intervention site female peers & 273 & 0.84 & 0.23 & $0.63-1.12$ \\
Intervention site male peers & 308 & 1.10 & 0.45 & $0.84-1.45$ \\
\hline
\end{tabular}

Note: Controlling for age and urban-rural residence

In focus group discussions, Girl Guides expressed their support for people living with HIV, including a willingness to buy food from someone living with HIV. According to one FGD participant:

I will buy from [him] because the money will help him go to hospital.

Girl Guide, Naivasha intervention site

\section{Knowledge of HIV and AI DS}

Although the HIV/AIDS peer education program aimed to improve knowledge level of the pupils, the results suggest that the intervention was not consistently associated with an increase in knowledge among any of the surveyed groups, including Girl Guides (see Table 11). For example, in the intervention sites, while there was a statistically significant increase in the proportion of respondents who knew that "HIV and AIDS were not the same thing "(29 percent at baseline vs. 39 percent at follow-up, $p \leq 0.05)$, and that "HIV cannot be transmitted by mosquitoes” (from 69 percent vs. 79 percent, $\mathrm{p} \leq 0.05$ ), there was a decline in the proportion who were correctly informed about the risk of HIV transmission from mother to child (from 81 percent to 70 percent, $\mathrm{p} \leq 0.05$ ). In addition, there were changes in the wrong direction in knowledge levels at the comparison sites between baseline and follow-up, such as a statistically significant decrease in the number of pupils who knew that "HIV is transmissible through unprotected sex.” 
Table 11 Knowledge about HIV and AIDS among pupils at intervention and comparison schools

\begin{tabular}{|c|c|c|c|c|}
\hline \multirow[t]{2}{*}{ Percent who: } & \multicolumn{2}{|c|}{ Intervention } & \multicolumn{2}{|c|}{ Comparison } \\
\hline & $\begin{array}{c}\text { Baseline } \\
\% \\
(n=1,109)\end{array}$ & $\begin{array}{c}\text { Follow-up } \\
\% \\
(n=1,160)\end{array}$ & $\begin{array}{c}\text { Baseline } \\
\% \\
(n=877)\end{array}$ & $\begin{array}{c}\text { Follow-up } \\
\% \\
(n=1,032)\end{array}$ \\
\hline Know that HIV and AIDS are not the same thing & 29 & $39 *$ & 30 & $33^{*}$ \\
\hline $\begin{array}{l}\text { Know that HIV is transmissible through unprotected } \\
\text { sex }\end{array}$ & 83 & 84 & 85 & $79 *$ \\
\hline $\begin{array}{l}\text { Know that pregnant mothers can infect their unborn } \\
\text { babies }\end{array}$ & 81 & $70^{*}$ & 75 & 73 \\
\hline $\begin{array}{l}\text { Know one cannot tell if someone has HIV by } \\
\text { looking at them }\end{array}$ & 41 & $43^{*}$ & 41 & 39 \\
\hline Know HIV is not transmissible by sharing utensils & 72 & 75 & 78 & 76 \\
\hline Know HIV is not transmissible by mosquito bites & 69 & $78^{*}$ & 78 & 76 \\
\hline
\end{tabular}

*Differences between baseline and follow-up statistically significant $(p \leq 0.05)$

An aggregate knowledge score was generated by awarding a point for each correct answer. Thus the scores range from zero (all answers incorrect) to six (all answers correct). Bivariate analysis reveals no change in the aggregate scores between the baseline and follow-up surveys in either the intervention or comparison sites (data not shown). Thus the level of knowledge appears to have remained largely unchanged during the intervention. But this changed when confounders were controlled for. After dichotomizing the knowledge scores at the mean (low knowledge = three points or less; high knowledge = more than three points), Table 12 shows that compared to the comparison school girls, Girl Guides were 32 percent more likely to have high knowledge, while the other groups were not statistically different from the comparison school girls.

Table 12 Odds of having high knowledge by guiding status, follow-up survey

\begin{tabular}{lcccc}
\hline Group & $\mathbf{n}$ & Odds ratio & p value & $\mathbf{9 5 \% ~} \mathbf{C l}$ \\
\hline Comparison site girls & 771 & 1.00 & & \\
Girl Guides & 579 & 1.32 & 0.02 & $1.04-1.68$ \\
Intervention site female peers & 273 & 0.78 & 0.08 & $0.58-1.03$ \\
Intervention site male peers & 308 & 0.96 & 0.75 & $0.72-1.27$ \\
\hline
\end{tabular}

Note: Controlling for age and urban-rural residence

\section{Sexual Behavior}

Respondents were asked about their sexual activity to investigate whether involvement in the KGGA HIV/AIDS Peer Education Program had an effect on sexual risk-taking. At baseline Girl Guides in the intervention sites were the least likely to report ever having had sex (4 percent vs. 8 percent among their female peers and 27 percent among their male peers). Girl Guides were also the least likely to report 


\section{Hgrizons}

having had sex in the last six months (2 percent) followed by female peers ( 4 percent) and male peers (19 percent). Similar results were found among the respondents in the comparison sites.

At follow-up there was a slight increase in the proportions of respondents who were sexually experienced in both the intervention and comparison sites, and across all sub-groups examined. Compared to females in the comparison sites, Girl Guides and their female peers in the intervention schools were 1.7 times more to have ever had sex.

Table 13 Odds of ever having sex by guiding status, follow-up survey

\begin{tabular}{lcccc}
\hline Group & $\mathbf{n}$ & Odds ratio & $\mathbf{p}$ value & $\mathbf{9 5 \%} \mathbf{C l}$ \\
\hline Comparison site girls & 771 & 1.00 & & \\
Girl Guides & 579 & 1.72 & 0.01 & $1.14-2.60$ \\
Intervention site female peers & 273 & 1.79 & 0.03 & $1.08-2.97$ \\
Intervention site male peers & 308 & 7.32 & 0.00 & $4.95-10.86$ \\
\hline
\end{tabular}

Note: Controlling for age and urban-rural residence. Analysis for current sexual activity (had sex in previous six month) not conducted due to small sample sizes.

Both the baseline and follow-up surveys show that males in both the intervention and comparison sites were much more likely to be sexually experienced than females. Regression analysis of the follow-up survey data show that males were 7.3 times more likely to be sexually experienced than girls in the comparison schools.

\section{Perceptions of the I ntervention}

During focus group discussions the Girl Guides clearly expressed that they considered the general Girl Guide program to be an important part of their lives. They especially liked standing to attention and raising the flag, assembling in parade, and other activities that gave them high visibility. Many mentioned that they enjoyed the other activities conducted such as drama performances and first aid. They also liked what they were taught in the KGGA HIV/AIDS Peer Education Program, such as how to value their bodies.

Male and female peers, who were not members of the Girl Guides, but who, as a result of the ripple effect, were exposed to the HIV/AIDS Peer Education information, expressed favorable opinions of the program.

Moderator: What do you like about the [KGGA HIV/AIDS Peer Education] program?

Respondent: I like the way we are told, because there is no fearing or withholding any information. We are just told plainly.

Moderator: Why do you like it that way?

Respondent: Because we are told openly about even those sensitive matters.

Males peers, Naivasha intervention site 
Moderator: What have you learnt from the Girl Guides HIV/AIDS Peer Education Program?

Respondent 1: That I should be prepared for anything, that I can be infected or affected by HIV and AIDS.

Respondent 2: I have learnt that I should avoid peer pressure.

Respondent 3: To love and care for the HIV/AIDS victims.

Respondent 4: ...that I should chill and seal. I shouldn't have sex.

Female peers, Naivasha intervention site

The appeal of the program was also demonstrated by demands from boys to join the Girl Guides. As one Guide Leader reported:

...the boys do follow us and plead to join the group. We ask them to join the Abstinence Club.

Guide Leader, Malindi intervention site

FGDs indicated that Guide Leaders were committed and proud to be involved in the HIV/AIDS Peer Education Program. They valued the opportunity to contribute to the development of girls and young women, help them recognize their potential, and give them guidance regarding their choices in life. As volunteers, many felt they had personally gained from the activities, especially how to better relate to adolescents on sensitive topics like sexual behavior.

I also discovered some parts [of the body] that I had not known. As we went through the training, we were told it is not a shame to call the names [of the reproductive organs] as they are. So when I teach the girls, it is quite good because they will know exactly what they have and how to take care of it, and they will know how to protect themselves.

Guide Leader, Naivasha intervention site

For the first time I learnt something I did not know about HIV and AIDS. That the virus is not found in sperm or in the ova.... I also learnt about micro-cuts and how the virus can get in through those micro-cuts [during sex]. In my house I [am the mother of] adolescents, both boys and girls. I was able to talk to them....

Guide Leader, Naivasha intervention site

However, FGDs revealed that Guide Leaders faced some challenges while implementing the program, largely due to limited time and other competing activities in the school calendar. As a result, meeting times with the Girl Guides and other pupils were not regular, sometimes happening once a week, sometimes more often, and sometimes not at all. The duration of the meetings was also limited at times, sometimes to just half an hour. This is partly because Guiding is an extracurricular activity and partly because other teachers were sometimes with the pupils at the time the Guiding program was supposed to start, as a Guide Leader explained:

We are supposed to carry out [activities] once a week. There are times when there is no consistency because of interruption. Our school is quite busy...sometimes a teacher [is in the class] and we cannot tell them to get out so that we can have the girls. So we have not been very consistent. There are times when I have to use my lunch hour to compensate, but sometimes it is not easy.

Guide Leader, Naivasha intervention site 


\section{Hgrizons}

This time shortage contributed to the Guide Leaders not being able to complete all the topics they were supposed to cover. On average, Guide Leaders had covered about half the topics, although the manner in which they covered them varied. While most Guide Leaders started with the first topic in the manual, many then proceeded to the one they felt most comfortable or relevant after that. Others "touched" on most units:

It is not possible [to cover all the topics] because of time..... I have covered STI and HIV/AIDS but not all. I have not covered communication skills. Even with the ones I have, I have covered them but not all the topics or sub-topics in that topic....

Guide Leader, Naivasha intervention site

Time is a major factor. I have got limited time. It is only once a week and maybe the time I have planned to be with them, the teachers are still in class and maybe some pupils like those in Std. 7 and 8 have a lot of work.

Guide Leader, Naivasha Intervention site

Many Guide Leaders requested further training on the program, as they still felt they had gaps in their knowledge, particularly about home-based care. They considered this an important topic as several reported knowing children who are looking after parents and other loved ones who are infected with HIV. Other Guide Leaders felt it difficult to address certain topics. As some narrated:

[In discussing the topic of adolescent development]

Girls were shy and they were not free to name parts of the organs. Myself too... I can't. I am so shy [laughs]. So it was very difficult to guide them how to name those organs.

Guide Leader, Naivasha intervention site

I didn't understand why I should tell the girls to abstain and then tell them to prevent pregnancy. And especially in primary school... even if you tell them to prevent and they have gone through the sex, they are supposed to [observe] secondary virginity....

Guide Leader, Naivasha intervention site

Gender [was difficult to teach] because we have to convince the pupils to change their ways.... You can't even convince a boy to cook or fetch water because they already know that it is the work of girls.... It is very hard to convince them.

Guide Leader, Malindi intervention site 


\section{Discussion and Recommendations}

The results of the evaluation suggest that the KGGA HIV/AIDS Peer Education Program had a positive impact on the self-confidence and social connectedness of Girl Guides, and on their attitudes toward gender equity and people living with HIV. Regression analysis also shows that in the aggregate, Girl Guides were more knowledgeable than their schoolmates after the intervention. While there were positive changes reported for some of the aforementioned outcomes among male and female peers in the intervention schools, these findings, although statistically significant, are not large. Therefore, the program's greatest strength, as evidenced here, is its association with positive outcomes among the Girl Guides.

Girl Guides demonstrated the most consistent positive changes due to the intensity of their exposure to the intervention. Girl Guide Peer Educators had received an intense three-day training to become a Peer Educator. Following this training both the Peer Educators and the Guide Leaders conducted routine sessions with the Girl Guides to impart the information in the training manual via a myriad of activities. Thus Girl Guides were more intensively exposed to the program than other students in the schools. The results of this evaluation suggest that the program did not diffuse to the other students in high enough doses to positively impact their attitudes, knowledge, or behavior. This may be due to problems with implementation-Guide Leaders from about a third of the schools were transferred during the course of the school year, which interrupted the running of the program. In addition, other Guide Leaders did not have sufficient time or did not feel equipped enough to cover all of the material in the manual.

The following recommendations emerged from the study:

Strengthen program implementation. While the evaluation shows that the program was associated with several favorable outcomes, many improvements were small. It is important to recognize that the intervention had only been implemented for a year, probably an insufficient time to get the program to work optimally in all the schools and have it fully implemented as planned. Thus as the program is rolled out in other schools, more attention needs to be paid to supporting Guide Leaders to have adequate time and motivation to work with the Girl Guides, so that they carry out their role as peer educators on all of the designated topics.

Focus on increasing self-confidence and competence among students. The data show that there is still a need to instill a sense of self-assuredness and a competence among the adolescents. The program should emphasize skills building to resist peer pressure without feeling guilty — even after the program, nearly 40 percent of pupils in intervention sites said they would feel guilty if they refused to do what their friends wanted them to do. Nearly a third did not feel that they have someone they can talk to when then need help. Thus there remains a need to build and strengthen adolescents' feelings of support and selfconfidence.

Continue to address gender equity. While gains regarding gender equity were made during the intervention, nearly a third of respondents in intervention sites were not yet convinced that boys should do domestic work just like girls. Indeed some of the Guide Leaders themselves expressed difficulty promoting this notion. The data also show that while three quarters of adolescents in the follow-up survey in the intervention sites felt that boys should not be favored over girls in cases of financial difficulties, this implies that a quarter of adolescents in these sites either disagreed with this sentiment or were not 


\section{Hgrizons}

sure. Thus there is a need to further explore how gender equity can be instilled, both among the learners and among Guide Leaders themselves.

Incorporate informational and other strategies to reduce stigma. The data also show that many adolescents in intervention sites were still reluctant to buy food from a person living with HIV after the program. While the proportion who said they would buy food from a person living with HIV rose from 33 percent to 44 percent, this still means that more than half the adolescents in the intervention sites would not be willing to buy food from such an individual. Thus there remains an underlying fear of people living with HIV, which may be addressed by providing key information and through other stigma reduction strategies, such as face-to-face contact with people living with HIV.

Continue to promote abstinence and delay of sexual debut. A small increase in sexual activity among respondents was observed across all the groups in the study. But even after adjusting for age and urbanrural differences, girls in the comparison schools were less likely to be sexually experienced than the Girl Guides and the girls in the intervention schools. There may be several explanations for this difference. First, the Girl Guides may have felt more confident to disclose having had sex at follow-up compared to at baseline. In other words, some Girl Guides may not necessarily have had their first sexual experience between the data collection rounds, but may have just been more willing to disclose the truth at follow-up. During the intervention, Guide Leaders had encouraged the girls to be self-aware, self-accepting, selfconfident, and not to be shy especially regarding sexual matters.

Another explanation may be different temporal changes going on in the study communities that may have influenced actual or reported behavior. For example, in Naivasha, an intervention site, there had recently been a strong campaign on post-exposure prophylaxis, largely to encourage sexual assault victims to seek it within the 72-hour efficacy period. This could have de-stigmatized discourse on sexual activity among respondents from this site, making it easier for them to have disclosed prior sexual activity. Naivasha is also a significant commercial horticultural center, and of late has grown as a destination for domestic tourism. It is located on a trans-Africa highway, a major trucking route. It is also possible that the changes were due to factors that were not measured. Regardless of whether the differences between the intervention and comparison groups represent actual differences in sexual experience or just the reporting of it, the program should continue its promotion of abstinence and make sure that the girls have the knowledge, skills, and social support to carry out this behavior.

Address sexual activity among males. The data are consistent with other studies that show much greater levels of sexual activity among males; indeed males in intervention schools were more than seven times as likely to have ever had sex as the girls in the comparison schools. While the Girl Guide program aims to reach both males and females, the data suggest that a much more proactive approach at addressing males is urgently needed.

Ensure the provision of materials. Many Peer Educators reported not having key materials to carry out their roles. For example, half of the Girl Guide Peer Educators had not seen one of the main teaching aids they needed for their activities, "Talking Points". Therefore it is important that future interventions ensure that the Peer Educators have adequate supplies of materials and that these supplies are replenished periodically. Just as urgently is the need to avail materials for the learners. While the program tried to distribute youth-friendly booklets such as "Sara" comics, these were not widespread. Scale-up efforts should budget a sufficient supply of materials for the children to read and take home with them, so as to reinforce the messages acquired in school. 
Better brand the peer education program. Although the KGGA HIV/AIDS Peer Education Program intervention was not being conducted in comparison schools, the results suggest that activities similar to it may have been going on at sufficient enough depth as to be confused with the KGGA Peer Education program. It also suggests that the respondents may have confused the KGGA Peer Education program with some of the other extracurricular activities being conducted in schools such as the Child to Child, Why Wait etc. In Kenya, as in many other countries, there are a large number of HIV/AIDS education activities already ongoing in schools. Pupils are given books addressing HIV and AIDS, teachers are taught to infuse HIV and AIDS across subjects, and special guests (e.g., health care providers) are invited to talk with the pupils. Many extracurricular activities are directed toward addressing HIV and AIDS as well. Thus youth are reached with HIV messages both in and out of school.

Branding special programs that are implemented within the KGGA structure may help to minimize confusion among target audiences. A catchy, easy-to-recall brand name could have facilitated recall during the research, and minimized mistaken identities, especially because some teachers are patrons of several clubs that implement similar activities. For example, a teacher could be a Guide Leader but also be the patron of the Abstinence Club. While it makes for an efficient use of resources to reach more pupils, this also presented difficulties during the evaluation.

Branding could also help clarify some of the terms that could be commonly used to describe other programs, such as "Peer Educator." Informal discussions with the adolescents revealed that they considered themselves to be "Peer Educators" because they shared what they had learnt with their peers, even if they were not officially "Peer Educators" within the HIV/AIDS Peer Education program. Others were trained Peer Educators for other similar programs going on in schools such as Child to Child. Therefore this proliferation of HIV/AIDS activities made it difficult to untangle the true impact of the KGGA HIV/AIDS Peer Education program.

Engage Guide Leaders in discussions before expanding the program. Guide Leaders had many positive views about the program and how it can be strengthened, and expansion of the program could benefit greatly from further discussion with them. In particular, discussions should address the issue of time within the school curricula, materials and resources, meeting venues, and supportive supervision. Guide Leaders may also have helpful ideas about how to address the large differences between males and females with regards to sexual activity.

Strengthen program monitoring. Discussions with Guide Leaders suggest that future programs such as this one can benefit greatly from structured, proactive, and supportive program monitoring. This could be in the format of structured submissions of progress reports, structured visits from monitoring staff, and periodic supply of materials.

Visits from the training team can have great motivational impact on the Guide Leaders. A two-day midterm review and re-training can provide a valuable opportunity to share challenges, and to identify and solve problems promptly. Monitoring forms that document topics covered thus far, number of participants, and issues raised can provide strong indicators of how the program is progressing. 


\section{Hgrizons}

\section{References}

Hosmer, D.W. and S. Lemeshow. 2000. Applied Logistic Regression. New York: John Wiley and Sons Inc.

Ministry of Health. 2005. AIDS in Kenya: Trends, Interventions and Impact. $7^{\text {th }}$ Edition. Nairobi: Ministry of Health.

UNAIDS. 2004. 2004 Report on the Global AIDS Epidemic: $4^{\text {th }}$ Global Report. Geneva: UNAIDS. 


\section{Hgrizons}

Horizons is a global operations research program designed to:

- Identify and test potential strategies to improve HIV/AIDS prevention, care, and support programs and service delivery.

- Disseminate best practices and utilize findings with a view toward scaling up successful interventions.

\section{(2) Population Council}

Horizons is implemented by the Population Council in collaboration with

- International Center for Research on Women (ICRW)

- International HIV/AIDS Alliance

- PATH

- Tulane University

- Family Health International (FHI)

- Johns Hopkins University

For more information, please contact:

Horizons Program, Communications Unit 4301 Connecticut Avenue, NW Suite 280 Washington, DC 20008 USA

Tel: 202-237-9400

Fax: 202-237-8410

Email: horizons@popcouncil.org www.popcouncil.org/horizons 